\title{
La participación política de jóvenes universitarios de Hidalgo, México. Posibilidades y tipos*
}

\author{
The political participation of young university students in Hidalgo, \\ Mexico. Possibilities and types.
}
A participação política dos jovens universitários de Hidalgo, México. Possibilidades e tipos

Recibido el 24 de mayo de 2017. Aceptado el 31 de enero de 2018

\author{
Juan Antonio Taguenca Belmonte** \\ España \\ Robert González García*** \\ España
}

Para citar este artículo:

Taguenca Belmonte, Juan

Antonio y González García

Robert (diciembre, 2018). La

participación política de jóvenes

universitarios de Hidalgo,

México. Posibilidades y tipos.

Ánfora, 25(45), 219-256.

DOl: https://doi.org/10.30854/

anf.v25.45.2018.XXX

Universidad Autónoma de

Manizales. ISSN 0121-6538.

\section{Resumen}

Objetivos: describir la preferencia por la democracia, la participación política, la información, el interés y el acatamiento a las decisiones de las mayorías, asociándolas con edad y nivel educativo. Además, se busca tipificar la participación política de los jóvenes universitarios del Estado de Hidalgo, México e identificar su confianza en las instituciones

\footnotetext{
* Este artículo presenta resultados parciales de dos investigaciones financiadas por el Programa para el Desarrollo Profesional Docente, para el Tipo Superior (PRODEP) en el periodo 2016-2017. La primera lleva por título: "Democracia y políticas públicas: la ciudadanía en sociedades heterogéneas". La misma está incluida en la Red de Cuerpos Académicos de PRODEP: Ciudadanía y Democracia en Sociedades Diversas (RECEDES). La segunda se titula: "Participación juvenil estudiantil en perspectiva comparada". Ambas son llevadas a cabo por el Cuerpo Académico de Estudios Políticos Comparados, sito en el Instituto de Ciencias Sociales y Humanidades, Universidad Autónoma del Estado de Hidalgo. Una versión preliminar de este artículo fue presentada en el $9^{\circ}$ Congreso de la Asociación Latinoamericana de Ciencia Política (ALACIP), Montevideo, 26-28 de julio de 2017.

** Doctor en Ciencias Políticas y Sociología por la Universidad Autónoma de Barcelona, España. Profesor Investigador de la Universidad Autónoma del Estado de Hidalgo, México; Miembro del Sistema Nacional de Investigadores Mexicanos, nivel 1. Correo: juantaguenca@yahoo.com.mx

** Doctor en Ciencia Política y de la Administración. Profesor Investigador de la Universidad Autónoma del Estado de Hidalgo, México; Miembro del Sistema Nacional de Investigadores Mexicanos, nivel 1. Correo: rgonza67@gmail.com
} 
democráticas. Metodología: investigación documental sobre el contexto sociopolítico de Hidalgo. Se aplicó un método mixto con encuesta de ciudadanía y participación representativa en Hidalgo, lo mismo que entrevistas y grupos focales. Resultados: se evidenció preferencia por la democracia independiente de edad, género, nivel educativo e ingreso; también se halló desinformación, desinterés y poca participación política, desconfianza en las autoridades democráticas y poco acatamiento de decisiones mayoritarias. Los jóvenes universitarios hidalguenses sin participación política tienen un discurso sobre ésta basado en el temor; quienes participan convencionalmente poseen un discurso fundado en el realismo que defiende el impacto de la agenda política en la sociedad; y los que lo hacen con formas no convencionales mantienen un discurso de politización enmarcado en la falta de confianza en los mecanismos existentes de participación convencional. Conclusiones: los universitarios hidalguenses se sitúan en un contexto sociopolítico adverso a la participación política. Se expresan a través de tres tipos de participación política: no participantes (experiencial con baja participación), participación convencional (realista con participación en partidos) y no convencional (politizada con participación en movimientos sociales).

Palabras clave: Política; Participaciónjuvenil; Universitarios; Confianza institucional.

\section{Abstract}

Objective: to describe preference of democracy, political participation, information, interest, and observance of the majority's decisions whilst associating them with age and education level. Furthermore, this study aims to typify the political participation of young university students in the Hidalgo State, Mexico and identify their confidence in democratic institutions. Methodology: this documental research on the sociopolitical context in Hidalgo used a mixed method approach with a citizenship survey, representative participation of Hidalgo, interviews and focal groups were applied as well. Results: a preference for democracy was revealed, independent of age, gender, education level and income; moreover, the results found a disinformation, disinterest and little political participation, as well as a distrust in the democratic authorities and little observation of the majority's decisions. The young university students from Hidalgo who do not participate politically, have a discourse which is based on fear; those who participate conventionally posses a discourse founded in realism that defends the impact of the political agenda in society; and those who participate in non-conventional ways maintain a discourse of politicization defined in the lack of confidence in the existing mechanisms of conventional participation. Conclusions: the university students of Hidalgo are placed in a socio-political and adverse context as regards to political 
participation. They express themselves through three types of political participation: non-participants (experiential with low participation), conventional participation (realistic with participation in political parties), and non-conventional (politicized with participation in social movements).

Key words: Politics; Youth Participation; University Students; Institutional Confidence.

\section{Resumo}

Objetivo: descrever a preferência pela democracia, participação política, informação, interesse eadesão às decisões das maiorias, associando-as à idade e ao nível educacional. Além disso, procura-se tipificar a participação política dos jovens universitários do Estado de Hidalgo, no México, e identificar sua confiança nas instituições democráticas. Metodologia: pesquisa documentária sobre o contexto sociopolítico de Hidalgo. Um método misto foi aplicado com uma pesquisa de cidadania e participação representativa em Hidalgo, bem como entrevistas e grupos focais. Resultados: a preferência pela democracia independente de idade, gênero, escolaridade e renda foi evidenciada, também se achou desconfiança nas autoridades democráticas e pouco cumprimento das decisões por maioria. Os jovens universitários de Hidalgo sem participação política têm um discurso sobre essa questão baseado no medo; aqueles que participam convencionalmente têm um discurso baseado no realismo que defende o impacto da agenda política na sociedade; e aqueles que o fazem com formas não convencionais mantêm um discurso de politização enquadrado na falta de confiança nos mecanismos existentes de participação convencional. Conclusões: os universitários de Hidalgo se encontram em um contexto sociopolítico adverso à participação política. Se expressam através de três tipos de participação política: não participantes (experiencial com baixa participação), participação convencional (realista com participação em partidos) e não convencional (politizada com participação em movimentos sociais).

Palavras-chave: Política; Participação juvenil; Estudantes Universitários; confiança institucional. 


\section{Introducción}

Existen pocos estudios, y menos de orden subnacional, sobre las condiciones y cómo se da la participación juvenil. A este respecto, Vázquez (2011) señala que: "quedan pendientes reflexiones que ayuden a superar las limitaciones de los estudios que conciben la participación juvenil ligada a movimientos sociales y su poco interés en los procesos político-electorales” (pp. 46-47). Esta investigación se hace eco de esta deficiencia en los estudios sobre las juventudes y explora la participación política de los jóvenes universitarios hidalguenses.

La acción política juvenil es minoritaria, variada en su organización, fines y medios expresivos, espacial y temporalmente contextuada ${ }^{1}$, latente o explícita. Se puede manifestar mediante formas expresivas novedosas que son parte importante de las identidades grupales que las representan o mediante formas tradicionales de reivindicación y adhesión institucional. Entra en conflicto parcial o totalmente con el orden sistémico predominante o lo reproduce.

La mayoría de los jóvenes son aparentemente "indiferentes" y "apáticos" con respecto a la política y lo político². Indiferencia y apatía que surgen de su valoración negativa de los actores e instituciones encargadas de administrar lo público. Estos jóvenes no se organizan colectivamente ni se inscriben en organizaciones de representación o participación ciudadana. En ellos, la vida cotidiana está separada de las decisiones políticas o, en todo caso, creen no poder incidir en ellas.

En el artículo que se presenta también se consideran los jóvenes con actividad política. Son una minoría con respecto al total de los residentes en el Estado de Hidalgo ${ }^{3}$, México; pero son un referente importante a tener en cuenta en las variaciones y permanencias del imaginario juvenil sobre la política y lo político y las trasformaciones políticas y sociales que se produzcan en la entidad.

Las formas organizativas de estos jóvenes pueden ser convencionales, las cuales se ajustan a los valores dominantes y al mantenimiento del estatus quo existente. Ejemplo de ellas es la membresía en partidos políticos. También pueden ser no convencionales. Éstas se producen a través de organizaciones de la sociedad civil y movimientos reivindicativos puntuales o de más largo alcance, que ponen en evidencia los valores y el estatus quo dominante, al que quieren cambiar. Ambas formas de participación política ${ }^{4}$ juvenil tienen estrategias, ob-

\footnotetext{
1 Se incluye también a Internet que tiene tiempos y espacios diferenciados del "real".

2 Se habla de los jóvenes mexicanos en general y de los hidalguenses en particular. En Taguenca (2011) se analiza la relación de estos jóvenes con la política y lo político.
}

3 El estado de Hidalgo se ubica en México, situándose a 94 kilómetros de la capital del país, Ciudad de México.

4 Conway (1990, citado por Brussino, Rabbia y Sorribas, 2009, p. 279) señala que: "la participación 
jetivos, metas, formas organizativas, tácticas y acciones diferentes; pero en sus diversos contenidos, formas, formatos y contextos dan cuenta, en sus resultados de diverso tipo, del potencial de las juventudes como agentes políticos con capacidad de transformaciones parciales de las sociedades en las que se ubican.

Existe poca bibliografía sobre los universitarios de Hidalgo y su relación con la política; destacan al respecto: Taguenca (2011, 2012 y 2013). Hay alguna literatura sobre la cultura política de los jóvenes hidalguenses: Sánchez (2007), Molina y Ponce (2009). Las investigaciones realizadas sobre la relación de los jóvenes universitarios hidalguenses con la política en sus diversos aspectos son muy pocas, y las referidas a los universitarios del Estado son todavía menos. Esto justifica realizar una investigación sobre este tema tan poco tratado en Hidalgo; máxime cuando se aporta evidencia sobre la existencia de distintos tipos de participación política de los jóvenes universitarios hidalguenses y de cómo se configura.

El problema de investigación se constituye en torno a ¿cuál es el contexto sociopolítico en Hidalgo? y ¿cómo se da la participación política de los jóvenes universitarios hidalguenses? En cuanto a los objetivos, éstos fueron: identificar el nivel educativo, de ingresos, de heterogeneidad étnica y de crecimiento económico, comparándolos con el ámbito nacional (México) y de otros Estados; identificar el sistema político en Hidalgo; describir la preferencia por la democracia, información, interés y participación política, confianza en las autoridades y acatamiento de decisiones tomadas por una mayoría, asociándolas con edad, género, nivel de ingreso y nivel educativo (Contexto Sociopolítico de Hidalgo); comparar los resultados obtenidos aquí con los que se obtienen nacionalmente y de los otros Estados de México. Además, tipificar y comprender la participación política de los jóvenes universitarios del Estado de Hidalgo, México, así como su confianza en las instituciones democráticas. Todo ello es relevante, pues da conocimiento sobre el contexto sociopolítico de Hidalgo y de cómo participan en política los jóvenes universitarios hidalguenses.

\section{Metodología}

Se realizó una revisión documental llevada a cabo a través de estadísticas nacionales y del Estado de Hidalgo y de material bibliográfico empírico y teórico sobre esta entidad federativa. Se pasó después a implementar un diseño mixto de investigación: con utilización de encuestas, que permitieron medir y asociar,

política incluye todos aquellos comportamientos que realizan personas y grupos para influir en los asuntos públicos". 
y entrevistas y grupos de discusión que posibilitaron clasificar y comprender la participación política de la juventud universitaria hidalguense.

Las técnicas de investigación social que ordenan, asocian y miden diversos conceptos, operados a través de variables objetivadas que surgen de teorías empíricas, permiten explorar, describir, correlacionar o explicar, en el mejor y más complejo de los casos. Esto es importante en el sentido de obtener comprensiones parciales de los fenómenos estudiados.

No son suficientes, sin embargo, estos tratamientos cuantitativos de la realidad observada 5 . Se hacen necesarias técnicas cualitativas para ahondar en las realidades existentes, máxime cuando se está ante intermediaciones sociales tan importantes como las interrelaciones entre los jóvenes universitarios hidalguenses y la política. El proceso general comprendió las siguientes fases:

Se realizó una Encuesta de Ciudadanía y Participación (ECP a partir de ahora), a través de la empresa Data. Opinión Pública y Mercadeo, del 14 al 28 de diciembre de 2014 (Colegio Mexiquense A.C. y Data Opinión pública y mercadeo, 2014). La misma constó de 3200 entrevistas realizadas en los estados de: Oaxaca, Estado de México, Chihuahua e Hidalgo. La encuesta fue mediante muestra probabilísticas y representativa en los estados que se implementó. Se generaron, de esta manera, estimaciones que fueron aplicables a la población de interés. Esta fue, por edad de 18 años y más de ciudadanos mexicanos que viven en México. En Hidalgo se realizaron 500 entrevistas con un +/-4.4 de error teórico. El marco muestral se realizó a través del Marco Geo-estático Nacional en áreas urbanas y rurales (menos de 5000 habitantes) según el censo de vivienda 2005. El muestreo fue multietápico y por conglomerados siguiendo el método aleatorio y seleccionando a través de él hogares en los que sólo se entrevistaba

\footnotetext{
5 Esto se inscribe en la clásica disputa epistemológica del método de las ciencias sociales. Por un lado, pensadores que creen en un único método para éstas y las ciencias naturales, como Popper y Albert, por ejemplo; por otro lado, filósofos dialécticos: Adorno y Habermas, entre otros, que piensan en una dualidad metodológica, dada la diferencia sustancial del objeto de estudio de ambas: la naturaleza es objetivable en sus partes al ser externa al hombre y por tanto puede ser estudiada a través de instrumentos de medición que corroboren determinados criterios epistemológicos previos (falsación, en el caso de Popper); la sociedad no es objetivable en sus partes solo en su totalidad, que además es cambiante, con base en la comprensión dialéctica. Esta diferencia sustancial deriva metodológicamente en un método cuantitativo que se hace eco de la verdad existente en la naturaleza y la sociedad con los mismos instrumentos (Popper, Albert); y un método cualitativo que intenta aprehender la totalidad social a través de la dialéctica, con instrumentos cualitativos. El rico debate sobre esta disputa del método se puede encontrar en Adorno et al. (1973). También en el caso de los teóricos de la Acción Participativa (Paul Oquist Paresh Chattopadhyay Michael Bodemann Heinz Moser Orlando Fals Borda Manfred Max Neeff, entre otros) las técnicas de investigación social utilizadas son las denominadas cualitativas, lo que resulta de su concepción epistemológica. Al respecto, tienen: "una relación entre teoría y práctica investigadora abierta, creciente y en construcción, la acción alimenta a la teoría y viceversa. Se parte de la experiencia y saber cotidianos, luego se lleva a estos a un nivel de descripción, luego a uno de explicación, luego a uno de transformación para después recomenzar el proceso" (Ochoa, s.f., p. 4).
} 
una persona de 18 o más años. Finalmente, se ajustaron por sexo y edad cuotas considerando la distribución del Censo General de Población y Vivienda $2010^{6}$.

La encuesta contenía 6 dimensiones: 1) preferencia por la democracia $\left.{ }^{7}, 2\right)$ información política $\left.{ }^{8}, 3\right)$ interés en la política $\left.{ }^{9}, 4\right)$ participación política $\left.^{10}, 5\right)$ uso y efectividad $^{11}$ y 6 ) acatamiento de decisiones mayoritarias ${ }^{12}$. De las mismas interesaban los resultados al cruzarlos con variables transversales: género, nivel de in-

6 La nota metodológica completa se puede consultar en: Colegio Mexiquense y Data Opinión Pública y Mercadeo (31 de diciembre de 2014).

7 Esta dimensión viene referida a una ordenación ordinal, por parte de los entrevistados, entre las distintas formas de gobierno. Al respecto, según el Instituto Federal Electoral (s.f.) existe una valoración positiva, casi universal, respecto a la democracia.

8 Esta variable se construyó a través de cuatro preguntas coyunturales en el momento de levantar la encuesta: 1. ¿Quién es el presidente del PAN nacional?; 2. ¿Sabe usted de qué sindicato es líder Carlos Romero Deschamps?; 3. ¿Cuáles son los principales partidos políticos en conflicto en la izquierda mexicana?; 4. ¿Cuántas elecciones para gobernador habrá el próximo año? Las preguntas vienen referidas a información política de carácter general y pueden ser fácilmente respondidas siguiendo con alguna frecuencia los medios de comunicación de carácter general. Es probable, que con otros tipos de preguntas los resultados obtenidos hubiesen variado en algo, pero la elección realizada es pertinente y similar a encuestas mexicanas, como la Encuesta de Valores lo que nos une y divide a los mexicanos (ENVUD, 2010) y la de Cultura Política (ENCUP, 2012) que indagan sobre estas dimensiones, y cuyos resultados son similares a los nuestros.

9 Jorge (s.f.) refiere que el interés en la política es una variable actitudinal multidimensional que está relacionada con: el nivel educativo, el tipo de ocupación, la pertenencia a organizaciones voluntarias, la frecuencia de encuentros con los amigos, la confianza interpersonal, la adhesión a valores democráticos, la edad, el tamaño de la localidad y el nivel de ingreso.

10 Fernández (1999) define la participación política como: "el conjunto de actividades, interacciones, comportamientos, acciones y actitudes que se dan al interior de una sociedad en forma individual o colectiva por parte de individuos, grupos, partidos e instituciones, las cuales van dirigidas a explicar, demandar, influir o tomar parte en el proceso de decisiones políticas..."

11 La medición de esta variable se realizó a través de la pregunta: Para resolver un problema que le afecta a usted y a otras personas ¿ha tratado de...? Las posibles respuestas fueron: 1. Procurar el apoyo de partidos políticos o senadores; 2. Hacer una denuncia en medios de comunicación; 3. La gente como usted no tiene nada que decir de lo que hace el gobierno; 4. Buscar un líder que sea capaz de resolver el problema; 5. Recurrir a las autoridades gubernamentales y 6. Organizarse con otras personas afectadas. Se trata en esta dimensión de medir cómo resuelven sus problemas los ciudadanos hidalguenses. Esta pregunta se basa en la pregunta 56 de la ENCUP (2012): "Para resolver un problema que afecta a usted y a otras personas, ¿alguna vez ha tratado de ..."

12 La pregunta que se utilizó para medir esta dimensión fue: "Si en una junta de vecinos, la mayoría toma una decisión que es injusta y que lo perjudica solo a usted o su familia ¿Qué haría?". Las posibles respuestas fueron: 1) sí obedecería la decisión; 2) no obedecería la decisión; y 3) pediría a la autoridad que la decisión se aplique a los demás. Se trata en esta dimensión de medir cuántos entrevistados acatarían una decisión mayoritaria que les afecte. Recordemos que la regla de la mayoría: "fue concebida como el procedimiento necesario, o el más idóneo, para la formulación de una decisión colectiva en las universitates, es decir, en asociaciones de personas en que la unión de los individuos produce un sujeto colectivo diferente de sus partes y superior a ellas" (Bobbio, 2009, pp. 464-465). 
gresos $^{13}$, edad ${ }^{14} \mathrm{y}$ nivel educativo ${ }^{15}$, sobre todo. Por último, se realiza un Análisis de Tablas de Contingencia (ATC) para establecer dependencias y asociaciones entre las variables y las variables transversales.

La encuesta dio resultados interesantes sobre la poca participación política de los ciudadanos hidalguenses, incluso en niveles altos de educación. Ello lleva a preguntar si realmente los universitarios hidalguenses no tienen participación política o sí la tienen, y en este caso, en qué consiste y qué diferencias existen en ella. Para responder a estas preguntas era necesario aplicar técnicas de investigación cualitativas.

En el sentido señalado, se llevaron a cabo 9 entrevistas semidirigidas entre febrero y marzo de 2016 y 3 grupos focales, con 23 participantes, en abril de 2016. En total fueron 32 jóvenes estudiantes o titulados universitarios entre 18 y 29 años. Estos se seleccionaron por sus formas de participación política, que teóricamente se define como: convencional ${ }^{16} \mathrm{y}$ no convencional ${ }^{17}$. Incluyendo también algunos no participantes en cuanto que se quiere comprender su no participación política o participación esporádica. . Esta división permitió indagar sobre las cinco tipologías de relación de los jóvenes con la participación política descritas por Megías (2006).

Es necesario señalar que la selección de los entrevistados y participantes en los grupos focales no fue aleatoria ni probabilística sino orientada a la obtención de discursos de subconjuntos poblacionales universitarios con participación política convencional: militantes de las juventudes de los partidos políticos siguientes: Partido Revolucionario Institucional (PRI), Partido de Acción Nacion-

\footnotetext{
13 Para poder determinar el nivel de ingreso se utilizó como pregunta de referencia el número de focos que el ciudadano tiene en su casa, con el siguiente criterio: menos de 7 focos el tipo de ingreso era bajo; entre 8 y 11 focos la categoría era ingreso medio; 12 o más focos el criterio era ingreso alto. Se trata sólo de un indicador parcial del nivel de ingreso de una familia que habría que completar con otros, con otras variables. En este sentido, la Asociación Mexicana de Agencias de Investigación de Mercados y Opinión Pública (AMAI, mayo de 2008) contempla: "seis niveles a partir de 13 variables", en la que una de ellas es el número de focos.
}

\section{Considerando para el análisis a los jóvenes, aquellos que tenían una edad que iba de 18 a 29 años.}

15 El nivel educativo se categorizó en tres niveles: estudios de secundaria, bachillerato y universidad o más. Por otro lado, Taguenca y Lugo (2011) afirman que: "el nivel educativo tiene una repercusión importante en la formación política que incide directamente en la participación ciudadana en la esfera pública” (p. 185).

16 Tipo de acción política que se considera adecuada y ajustada a los valores dominantes, referida principalmente a la afiliación partidaria o al voto (Martí y Llamazares, 2011). En esta categoría se incluyen: los discursos referidos al sufragio, la adhesión a institutos electorales y la militancia en partidos políticos, las actividades vinculadas a organizaciones no gubernamentales, las organizaciones de la sociedad civil y las sociedades de alumnos.

17 Se incluye en este tipo de participación no convencional: marchas, paros, tomas de espacios públicos, adhesión a colectivos e implicación en actividades por medio de vínculos con grupos primarios. 
al (PAN), Partido de la Revolución Democrática (PRD), Partido Movimiento de Regeneración Nacional (MORENA), Partido Nueva Alianza y miembros de La Sociedad de alumnos de la Universidad Autónoma del Estado de Hidalgo (UAEH).

En cuanto a la participación política no convencional los universitarios entrevistados y participantes en grupos focales pertenecían a los movimientos estudiantiles y sociales \#Yo Soy 132 y el movimiento solidario con los 43 de Ayotzinapa, que tenían una gran repercusión entre los jóvenes, sobre todo estudiantes, en el momento de realizar el trabajo de campo. Entre los jóvenes participantes en las entrevistas y grupos de discusión había quienes participaban en estos dos movimientos sociales, con mucha repercusión entre los estudiantes universitarios, y que luego participaron en movimientos ciudadanos como el referido a la imposición de un nuevo sistema de transporte en Pachuca denominado: "Tuzobus".

No había, sin embargo, entre los jóvenes algunos que participaran al mismo tiempo de una forma convencional y no convencional; esto no indica que sean compartimientos estancos, pues ambos se relacionan en el espacio público y pueden coincidir en algunas reivindicaciones, aunque no en las formas de llevarlas a cabo. Se incluyeron algunos universitarios que no tenían participación o la tenían escasamente; para ello se tomó en cuenta el género al que pertenecían, el rango de edad que los situaba como jóvenes, y que fueran universitarios.

La muestra de universitarios seleccionados se hizo a través de la técnica de bola de nieve en función de tres tipologías de participación distribuidos de la siguiente forma: participación convencional: 3 entrevistas semidirigidas y 5 participantes en grupos focales; participación no convencional: 4 entrevistas semidirigidas y 6 participantes en grupos focales; no participantes: 2 entrevistas semidirigidas y 9 participantes en grupos focales. La composición por género fue de 19 hombres y 13 mujeres, quedando sobrerrepresentados los hombres tanto en las dos tipologías participativas y no así en la de no participantes. En cuanto a la edad, la mayoría de los estudiantes seleccionados (21) tenían entre 18 y 23 años, mientras que el resto (11) tenían entre 24 y 29 años.

En relación con el proceso que se aplicó, en la primera fase de la investigación cualitativa se realizaron las entrevistas semidirigas, las que orientaron, a través de las opiniones emitidas por los entrevistados, la guía de los grupos focales, los cuales se llevaron a término en la segunda fase.

Se establecieron dos etapas para comprender las formas de participación política de los jóvenes universitarios hidalguenses: (1) distinción de las distintas formas de participación a través del análisis de contenido de los discursos emitidos tanto en las entrevistas como en los grupos focales; (2) comprensión de las 
características principales de los distintos tipos de participación política de los universitarios hidalguenses.

Si bien no se pueden generalizar los resultados en este diseño de investigación cualitativa, sí son orientadores sobre las características que reúnen los tipos de participación señalados, incluso de los no participantes, al tiempo que permiten obtener una comprensión exploratoria de los mismos que posibilita nuevas investigaciones más explicativas.

\section{Resultados}

La participación política de los jóvenes universitarios hidalguenses se enmarca en posibilidades derivadas del contexto sociopolítico en que se desenvuelven. Este se identificó a través de estadísticas realizadas por el INEGI: el nivel educativo, de ingresos, de desarrollo, riqueza y marginación, comparándolos con los de otras entidades federativas. También se destaca la multietnicidad de este Estado. El sistema político, a su vez, se identificó a través de literatura teórica y empírica especializada que tiene a Hidalgo como objeto de estudio.

Se distinguieron tres tipos de participación política de los jóvenes universitarios hidalguenses: convencional, no convencional y no participantes, y se comprendieron cuales eran sus similitudes y diferencias, a través de entrevistas y grupos focales. Por último, se identificó la confianza en las instituciones democráticas que tienen estos jóvenes.

\section{Contexto sociopolítico para la participación de los jóvenes universi- tarios hidalguenses}

Hidalgo se sitúa en las inmediaciones de Ciudad de México, sólo 90 Kilómetros separan su capital, Pachuca de Soto, de la del país, siendo ésta la más próxima en distancia de las existentes en las distintas entidades federativas. Este Estado es paso obligado entre las provincias del norte y del golfo con el Distrito Federal, estando además cerca del bajío. Colinda al norte con Querétaro, San Luis Potosí y Veracruz de Ignacio de la Llave; al este con Veracruz de Ignacio de la Llave y Puebla; al sur con Puebla, Tlaxcala y México; al oeste con México y Querétaro. Ocupa sólo el $1.1 \%$ de la superficie del país.

A 15 de marzo de 2015 Hidalgo tenía una población de 2858 359, que se distribuían por sexo de la siguiente forma: 1369 o25 hombres y 1489 334 mujeres; de entre el total de estos: 703763 (24.62\%) tenía una edad comprendida entre los 
15 y los 29 años. En este rango de edad había 338989 (24.76\% de los hombres de la entidad) y 364774 (24.49\% de las mujeres) (INEGI, 2016) ${ }^{18}$.

El Estado tiene una población en situación de pobreza, en 2014, de 1547 812, que representa el 54.3\% de sus habitantes, de éstos 350456 (12.3\%) se encuentran en situación de pobreza extrema y 1197356 (42\%) en pobreza moderada. Otro indicador sobre la pobreza que sufren los ciudadanos de Hidalgo es que 1693 859, el 59.4\%, tienen un ingreso inferior a la línea de bienestar cuadro $\left(\right.$ INEGI, 2016) ${ }^{19}$.

El Estado de Hidalgo se caracteriza también por el rezago educativo ${ }^{20}$ y una gran diversidad étnica, con varios grupos de pueblos originarios dentro de él que suman 359972 personas (13\% del total de habitantes de la entidad), con el Náuatl y el Otomí como los pueblos más importantes (INEGI, 2013); y “poco crecimiento económico, generación de empleos formales, productividad, pobreza laboral, informalidad y desigualdad laboral" (Trejo, 3 de agosto de 2017, p. 18).

El sistema político en Hidalgo es de partido predominante ${ }^{21}$, con el Partido Revolucionario Institucional (PRI) como aglutinador, en buena parte, de las élites locales; y una cultura política súbdita o clientelar que favorece el clientelismo y fomenta el conservadurismo, el mantenimiento del estatus quo y la dependencia de los individuos con respecto a liderazgos autoritarios.

Al respecto de lo anterior, Acosta y Tapia (2003) encontraron resultados interesantes, con respecto a Hidalgo, en su revisión de la Encuesta Nacional de Juventud de 2000. En este sentido, una de sus conclusiones es que la sociedad hidalguense está: "rodeada de una "alta moralidad”, que a la larga actúa en contra de las libertades de los individuos, que fomenta creencias y limita su accionar, enconándolos en los esquemas que más convenga a los operadores políticos” (p. 34).

18 Concretamente en el cuadro 3.1.

19 Estos datos se encuentran en el cuadro 3.28.

20 Si bien Hidalgo se sitúa en el primer lugar, sobre 32 estados, en el porcentaje de población de 6 a 14 años que asiste a la escuela por entidad federativa, se coloca en la tasa de analfabetismo de la población de 15 años y más por entidad federativa en séptimo lugar, en el $24^{\circ}$ en promedio de escolaridad de la población de 15 años y más por entidad federativa y entra en el segundo grupo de peor clasificados en la estratificación de las entidades federativas según promedio de escolaridad de la población de 15 años y más (INEGI, 2015, pp. 29, 34, 36, 37).

21 Aunque durante buena parte del periodo posrevolucionario fue un sistema de partidos con un actor hegemónico, el PRI. Tan sólo desde hace unos pocos lustros, el sistema se havuelto de partido predominante, lo que ha dado más juego a otras fuerzas políticas (Partido de Acción Nacional y Partido de la Revolución Democrática, sobre todo), sobre todo a nivel municipal; aunque esto no ha significado alternancia a niel de ejecutivo y de parlamento local, si se ha producido realineamiento de votos y una mayor competencia, lo que ha significado que el Revolucionario Institucional haya realizado alianzas con partidos pequeños en diversos distritos electorales, principalmente con el Partido Verde Mexicano y con Nueva Alianza. 
Por otro lado, un estudioso de las relaciones políticas y sociales en Hidalgo, Vargas (1990), señala que:

La historia política del estado de Hidalgo ha sido la historia de grupos de poder regional, pequeño número de familias que se han alternado el poder en la entidad desde hace más de 50 años... En este tiempo se desarrolló una estructura de explotación económica y dominación basadas en el caciquismo, alimentadas por antiguas tradiciones... Como reflejo de la estructura socioeconómica el ejercicio personalizado del poder forjó una cultura política en que sus lenguajes, prácticas y símbolos se basaron en relaciones personales de confianza, lealtades, nepotismo, compadrazgos y amiguismos (pp. 132-133).

Trabajos más recientes -como los de Taguenca (2011), que utiliza encuestas, entrevistas y narrativas que se aplican a un amplio grupo de universitarios hidalguenses- confirman la permanencia de estos resultados, aunque con algunos matices que no los alteran en lo sustancial.

Lo anterior, con el sustento de los trabajos empíricos y teóricos señalados, permite comprender algunas de las razones importantes que están detrás de que la ciudadanía de los jóvenes en Hidalgo pasa mayoritariamente por el sufragio y se da en sentido vertical: de las administraciones públicas al ciudadano. Es decir, a aquel se le da información y se le comunica pero no se le permite intervenir en la toma de decisiones de política pública y en el control de la misma.

Respecto a la ordenación, asociación y medida, la ECP informa de la opinión ciudadana, incluida la de los jóvenes, sobre aspectos fundamentales de ciudadanía. En relación con la preferencia por la democracia, los resultados de la $\mathrm{ECP}^{22}$ señalan que el $54.3 \%$ de los hidalguenses entrevistados la prefieren a otra forma de gobierno. No deja de ser preocupante, sin embargo, que al 40.6\% o le dé lo mismo una forma de gobierno autoritaria que democrática o que prefiera la primera a la segunda en algunas circunstancias. La preferencia por la democracia es independiente por edad, es decir, los jóvenes no prefieren esta forma de gobierno más que los adultos ni viceversa. Tampoco se observan diferencias de preferencia por la democracia por: género, nivel educativo o nivel de ingreso.

Estos resultados son similares a los obtenidos en la Encuesta Nacional de Valores de la Juventud -ENVAJ- (2012) que señala que el 45.2\% de los jóvenes mexicanos no simpatiza con ningún partido y que el $89.29 \%$ de ellos manifiesta desinterés por la política. 
Las causas de la desafección por la democracia de un amplio sector de jóvenes mexicanos son varias, Woldenberg (6 de diciembre de 2014) señala el malestar y desencanto social por la democracia naciente. En contexto global: Catells (2013) la atribuye al sumergimiento de "redes de indignación y esperanza"; Beck y Beck-Gernsheim (2003) dicen que se debe a un actitud juvenil centrada en la "generación del yo" que rechaza el excesivo formalismo de las instituciones democráticas y que aboga por una participación menos formalizada expresada en organizaciones como Greenpeace y en los movimientos sociales.

Cano (2015) imputa el hecho de la inconformidad al cierre del campo político con sus formas institucionales procedimentales, que generan desigualdad y antagonismos generacionales conflictivos en torno a nuevas formas de entendimiento e intervención en la sociedad, mismas que constituyen disidencias múltiples y antagónicas respecto al relato que la democracia liberal mexicana hace de sí misma. Por último, varios autores atribuyen la desafección por la democracia a la inconformidad de la ciudadanía con los resultados de las políticas públicas, lo que provoca su alejamiento de ésta y de sus instituciones (Krauze, junio de 2016; Maffesoli, 2009).

Las consecuencias de la desafección por la democracia se manifiestan en términos de deslegitimación y confianza en sus instituciones y procedimientos. En este sentido, como recuerda Rosanvallon, 2008, citado por Gómez et al. (2012):

...la confianza que los ciudadanos conceden a un proceso electoral o al ejercicio de gobierno [en un régimen democrático] es un economizador institucional que permite ahorrarse un conjunto de mecanismos de verificación y prueba para permitir que el sistema funcione con eficiencia. Si la confianza en las instituciones de la democracia desaparece..., la ciudadanía cuestiona los fundamentos de la democracia procedimental para intentar compensar la erosión de la confianza mediante una organización de la desconfianza..., una desconfianza que sistemáticamente se erige como un contrapoder ciudadano. Podríamos hablar entonces no de una cultura política, sino de una contracultura democrática en la que la desconfianza se convierte en un lastre para el funcionamiento del régimen (pp. 5-6).

La cita es importante a la hora de enmarcar lo que significan los resultados de la encuesta en torno a la preferencia por la democracia de los jóvenes hidalguenses. En este sentido, ésta tiene su base en la confianza por este régimen de gobierno, el cual se vuelve eficiente en la medida en que la misma sea lo suficientemente alta, es decir, alcance el umbral que le permita situarse como economizador situacional. 
El problema surge con porcentajes bajos de confianza en las instituciones democráticas, lo que se traduce en: "organización de la desconfianza”, "contrapoder ciudadano" y "contracultura democrática”; aspectos, todos ellos, que dificultan enormemente el funcionamiento de la democracia y sus instituciones.

Los resultados de la encuesta muestran un umbral de preferencia por la democracia que no permite ahorrarse los mecanismos de verificación y prueba. Esto hace más costoso el funcionamiento institucional, al tiempo que hace más ineficiente e ineficaz la toma de decisiones en política pública. Aunque ambas consecuencias son importantes, lo es más el peligro que corre la democracia si un umbral importante de ciudadanos la deslegitima como forma de gobierno.

Sobre la información política, medida en porcentajes, el 90.9\% de los hidalguenses entrevistados no acertó ninguna pregunta o sólo acertó una, lo que da cuenta de su desconocimiento sobre temas relacionados con la política nacional. Sólo el género y el nivel de estudios se relacionan, aunque en un grado bajo, con la información política: los que tienen un mayor nivel de estudios y los hombres los que tienen relativamente una mayor información política en Hidalgo. Ni el nivel de ingresos ni la edad están asociadas a una mayor o menor información política de los ciudadanos de la entidad. La condición de estudiantes de los jóvenes hidalguenses estudiados en este trabajo es importante para explicar su mayor y mejor información con respecto a la política que el resto de la población.

La Encuesta Nacional de Valores de la Juventud, ENVAJ, (2012) muestra resultados similares en el ámbito nacional. A la pregunta: “¿Qué tan seguido lees el periódico?”, pregunta que mide que tanto se informan los jóvenes, sólo el 9.6\% contestó que "una vez al día” y el 20.5\% "una vez cada semana” y la respuesta más alta fue "nunca” con el 39.4\%.

Fernández (2003), respecto a la relación entre información política y nivel de estudios dice que:

Los diferentes grados de información de los estudiantes van ligados a la escolaridad, al hecho de que el centro educativo sea privado o público, a la profesión paterna y al nivel socioeconómico [...] La conclusión apunta que si bien el sistema universitario contribuye a incrementar el interés y la información política entre los jóvenes, los estudiantes consultados no parecen tener grados muy altos en estas dos cuestiones, máxime tratándose de grupos pertenecientes a licenciaturas especializadas en problemas sociales y políticos, lo cual, más que con los centros universitarios en particular, tiene que ver con el bajo nivel del sistema educativo en general (p. 148). 
Las consecuencias de la baja información política generalizada son: el poco conocimiento sobre los mecanismos de las instituciones democráticas de toma de decisiones en política pública y su administración. Esto conduce también a percibir la política como una caja negra con poco y complicado acceso, separada de la vida privada e incluso contraria a la misma, al regirse por códigos que permiten la inequidad y la corrupción ${ }^{23}$.

Otra variable importante considerada en esta encuesta fue la de interés en la política. Pues bien, los resultados de la ECP indican que el desinterés de los ciudadanos de Hidalgo en ella es muy alto. Al respecto, el 77.4\% están poco o nada interesados en ella. Solo existe asociación en esta variable con el nivel educativo, ya que a mayor grado educación mayor interés por la política. No existe asociación entre interés por la político con la edad, el género y el nivel de ingresos. De nuevo la condición de estudiantes de los jóvenes investigados es la que marca su mayor interés por la política con respecto a los demás ciudadanos. Esto también se encuentra en la Encuesta Nacional de Valores de la Juventud (2012).

En cuanto a participación política, el $72.3 \%$ destaca sobremanera la participación electoral con el $72.3 \%$. Sólo el $12.7 \%$ de los entrevistados manifiesta haber participado en consultas ciudadanas, el $6.4 \%$ en asociaciones civiles, el $5.1 \%$ en marchas y el $4.9 \%$ en partidos políticos. Son los mayores de 30 años y los que tienen un mayor nivel de estudios los que están asociados a niveles altos de participación en Hidalgo ${ }^{24}$.

La participación política entendida como el ejercicio del sufragio es una de las bases fundamentales en la que se asientan las democracias liberales, pues legitima el ejercicio del poder con base a un mandato surgido de la elección de una mayoría de votantes, con derecho a votar, que eligen una opción entre las disponibles. Con la emisión del sufragio y la obtención del puesto de representación pública, los representantes quedan capacitados para la toma de decisiones públicas que afectan al conjunto de la comunidad política. El problema surge cuando una mayoría de ciudadanos se abstiene de emitir su voto, deslegitimando de esta manera a los electos y volviendo difícil su acción de gobierno al no disponer del respaldo popular suficiente. Este problema es poco acusado en nuestra entidad según los datos de la encuesta.

También es importante señalar tipos de participación más activa y que requieren mayor compromiso. Éstos son los que profundizan la democracia y los que están detrás de una mayor y más intensa participación en la esfera pública. En Hidalgo, los porcentajes de este tipo de participación son bajos, lo cual inci-

23 De hecho, México es el que tiene el nivel más alto de percepción de la corrupción de los 34 países que conforman la OCDE (Animal Político, 2015).

24 Se ven en próximos apartados en qué y cómo participan los estudiantes universitarios hidalguenses. 
de negativamente en un tipo de democracia más participativa y plural. A nivel nacional, también son pocos los jóvenes que participan en organizaciones institucionalizadas, por ejemplo en partidos políticos $(2.09 \%)$ o sindicatos $(1.24 \%)$ (Gómez et al., 2012).

Lo anterior no quiere decir que no haya jóvenes que participen con mecanismos convencionales de participación y tampoco que el resto no participe en absoluto, pues hay jóvenes que participan con formas no convencionales ${ }^{25} \mathrm{y}$ otros que lo hacen de forma esporádica de distintas maneras. En este sentido, Megías (2006, citado por González y Hernández, 2017) propone cinco tipologías:

En primer lugar estarían los jóvenes que muestran gran desinterés por que consideran que la política no es de su incumbencia...; un segundo grupo muestra rechazo hacia los mecanismos formales de la política...; un tercero muestra desconfianza hacia la efectividad de la acción política y de los actores políticos; el cuarto y quinto grupo mostrarían interés hacia la política, pero unos con una clara adhesión al status quo (partidos, gobiernos e instituciones formales) y otros, al contrario, con un fuerte compromiso hacia la transformación social desde medios alternos a los partidos, priorizando los movimientos sociales y las estructuras no formales (p. 191).

Lo importante de esta propuesta es que permite vislumbrar realidades de participación política diversas y distintas, ampliando el campo de observación del investigador a grupos sociales más reducidos que la totalidad, pero con participaciones políticas diversas y desde distintas ópticas.

Ahondando en lo anterior, se tiene que aumentar todavía más el campo de observación para comprender qué sucede con la participación política juvenil, introduciendo nuevas categorías que permitan dar cuenta de sus variadas y cambiantes formas de participación, mismas que se dan también, cuando menos, des-

25 En cuanto a la participación convencional y no convencional: "El criterio más ampliamente difundido fue introducido por Barnes y Kasse (1979) quienes, al incorporar los actos contestatarios y diversas modalidades de protesta a la par del análisis de los modos electorales de participación, distinguieron entre la acción política convencional y la acción política no convencional. En las modalidades de acción no convencional incluyeron el participar en una sentada, en un boicot o una manifestación, participar de grupos ciudadanos, cortar rutas o calles, ocupar edificios públicos, involucrarse en huelgas ilegales y la desobediencia civil, entre otras opciones; las prácticas convencionales, por su parte, abarcaban el trabajar para un candidato o partido, informarse y discutir acerca de cuestiones políticas, asistir a un mitin político, convencer a una persona de que vote a determinado candidato y votar... Su amplia aceptación como criterio de clasificación no oculta, sin embargo, las indefiniciones respecto a qué prácticas deben ser incluidas en una y otra categoría, ni cuáles son las relaciones que guardan entre sí cada modo de participación" (Brussino, Rabbia y Sorribas, 2009, p. 280). 
de las prácticas culturales ${ }^{26}$, las imágenes culturales ${ }^{27}$, las estéticas ${ }^{28} \mathrm{y}$ las nuevas formas de comunicación digitales ${ }^{29}$ (Reguillo, 2013; Urteaga, 2011, citando a Feixa, 1993c; Aguilera, 2016 y Muñoz, 2016).

Respecto al uso y efectividad, los resultados de la ECP muestran que casi 45 ciudadanos de 100 consideran que organizarse con las personas afectadas puede ayudar a mitigar un problema; un poco menos de 24 opinan que se debe recurrir a las autoridades gubernamentales; un número parecido que buscarán un líder que sea capaz de resolver el problema. Cabe aclarar que estas alternativas, cuando se abordaron en la ECP, no eran excluyentes. Los resultados pormenorizados se ven en la figura 1.

Otra pregunta relacionada con el uso y efectividad fue: ¿Qué tanto cree que les interesa lo que piensa la gente como usted a las autoridades municipales? El resultado a esta pregunta fue contundente con respecto a la creencia que a las autoridades municipales, las más próximas a la ciudadanía, les importa poco o nada lo que piensan los ciudadanos: el $91 \%$ opinó en este sentido, mientras que sólo el $9 \%$ consideró que les importaba mucho. Por otro lado, no existe asociación de la variable "uso y efectividad" con las de edad, género, nivel de ingresos y nivel educativo.

26 Este autora señala que: "Ahí donde la economía y la política "formales" han fracaso en la incorporación de los jóvenes, se fortalecen los sentidos de pertenencia y se configura un actor "político" a través de un conjunto de prácticas culturales..." (Reguillo, 2013, p. 360).

27 Por imágenes culturales Cales Feixa se refiere: "al conjunto de atributos ideológicos, valores y ritos asignados específicamente a los jóvenes; 2) así como al universo simbólico que configura su mundo, expresado en objetos materiales (como la moda y los bienes de consumo) y en elementos inmateriales (la música, el lenguaje, las prácticas culturales y otras actividades). Las imágenes culturales son producto de las elaboraciones subjetivas de los jóvenes o de las instituciones que intervienen en su mundo" (Feixa, 1993c, p. 15, citado por Urteaga, 2011, pp. 41-42). Las instituciones políticas entran en este juego de relaciones entre distintas imágenes culturales que se complementan, superponen y contraponen formando nuevas imágenes culturales que son cambiantes generacionalmente.

28 Al respecto, Aguilera (2016) señala que: "...la política cultural de los jóvenes [se] escenifica en la cotidianidad (sus cuerpos, su sociabilidad, sus territorios más próximos)” (p. 234).

29 Estas nuevas formas de comunicación constituyen un "nuevo sujeto heterogéneo [que está] completamente conexo a un entorno múltiple: virtual y actual, selectivo y masivo, local y global, posicional y nómada al mismo tiempo..." (Muñoz, 2016, p. 77). Pues bien, este nuevo sujeto de composiciones identitarias múltiples difícilmente anhela integrarse en las instituciones democráticas construidas por el liberalismo y que se caracterizan, entre otros, por su comunicación vertical, formalismo burocrático, rigidez estructural y localización situacional tanto en espacio como en tiempo. 
Figura 1. Porcentaje de respuesta a la pregunta:

Para resolver un problema que le afecta a usted y a otras personas ¿ha tratado de...?

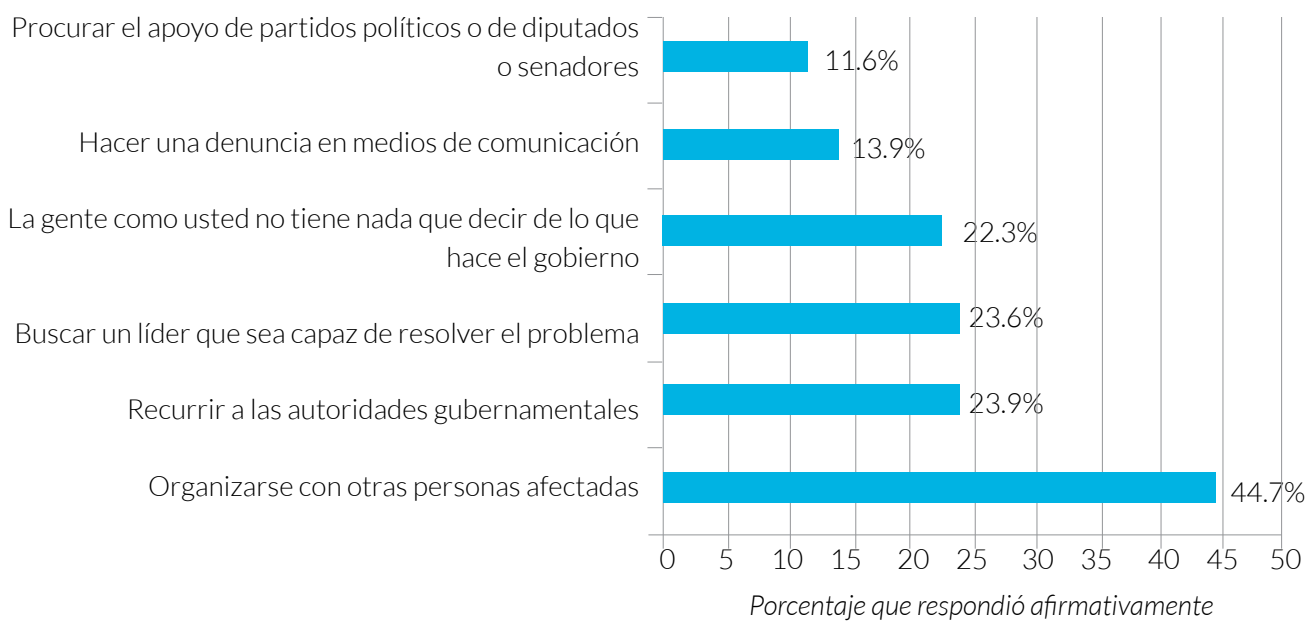

Fuente: elaboración propia a partir de las preguntas P30a1 a la P30a5 y P64d de la ECP (Colegio Mexiquense A.C. y Data Opinión pública y mercadeo, 2014).

En relación con la variable de acatamiento de las decisiones de la mayoría, sólo el $32.1 \%$ obedecería la decisión tomada, mientras que el $67.9 \%$ o no obedecería la decisión o pediría a la autoridad que se aplicara a los demás pero no a él. Lo que implica poco respeto por la regla de la mayoría, que es fundamental en democracia. No existe asociación de esta variable con las de edad, genero, nivel de ingresos y nivel educativo.

Por último, se comprueban los resultados con el promedio nacional ${ }^{30}$, obteniendo los siguientes resultados: Hidalgo (5.4) supera al promedio nacional (4.5) en la variable preferencia por la democracia; en información política, interés en la política, participación política y uso y efectividad se sitúa ligeramente por debajo, y en acatamiento de las decisión de la mayoría (4.4) supera al promedio nacional (3.8).

Como se observa no hay excesiva diferencia entre Hidalgo y el promedio nacional en este variable, aunque sí se sitúa mejor en preferencia por la democracia

30 Para realizar dicha comparación se normaliza cada variable en una escala de 0 a 10, en la que cero indica ausencia de y diez el mejor resultado posible. 
y en acatamiento de la decisión de la mayoría y peor en información, interés, participación en política y en uso y efectividad. Los resultados más pormenorizados se ven en la figura 2.

Figura 2. Preferencia hacia el régimen democrático

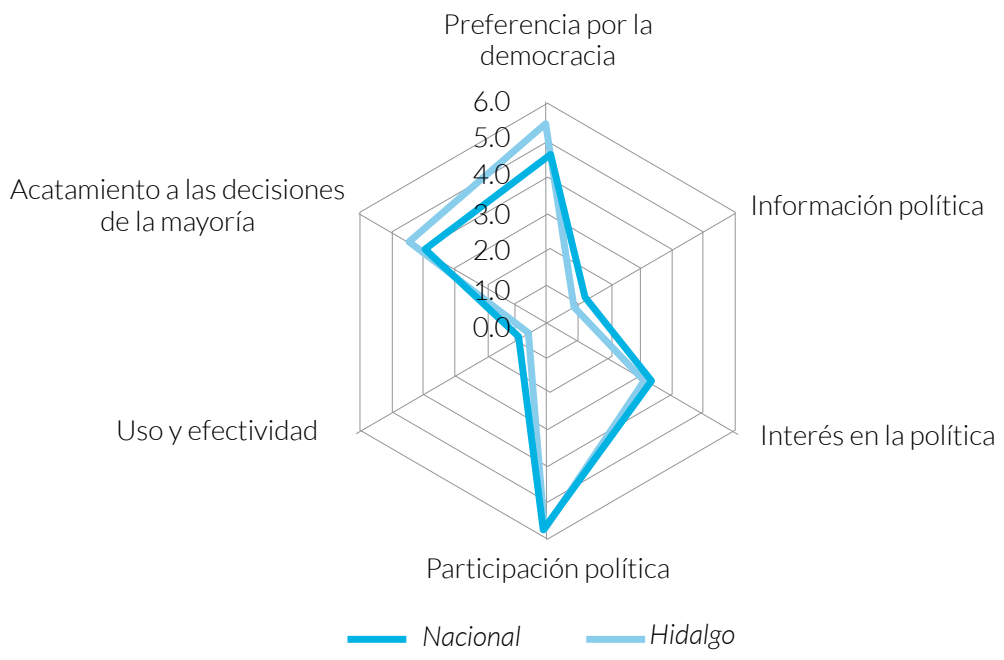

Fuente: elaboración propia a partir de la ECP (Colegio Mexiquense A.C. y Data Opinión pública y mercadeo, 2014).

El contexto sociopolítico en el que viven los universitarios hidalguenses es muy importante a la hora de poder identificar cuáles son sus posibilidades reales de participación política, pues las enmarcan.

La investigación quedaría, sin embargo, incompleta, de acuerdo con los objetivos planteados, si no se tipificara y comprendiera cómo ocurre realmente la participación política de estos jóvenes universitarios hidalguenses y su confianza en las instituciones democráticas. Ambos aspectos, importantes para los objetivos que se plantean, se introducen a continuación.

\section{La participación convencional de los jóvenes universitarios hidal- guenses}

Los militantes de partidos políticos, a pesar de que legitiman la participación convencional, también reconocen que existen otros tipos de participación tan o más importantes. Al respecto: 
"Mecanismos alternativos de participación al voto, yo creo que existen muchos..., que se constituyen desde la colectividad. El voto legitima el sistema democrático de participación político electoral, pero yo creo que además de lo político electoral está la construcción de la colectividad, desde: la formación de un comité de fábrica, de un comité de vecinos, de una cooperativa, etc. Esos son actos de ejercicio de democracia. No hay mayor democracia que la que se da en la base. Yo considero que más allá de la importancia del voto en el sistema político electoral, está la asimilación de la democracia como un estilo de vida. Insisto, democracia, ¿para quién? Pues democracia desde abajo... El hecho de participar en un partido político ya es un paso muy grande; pero la organización vecinal, la construcción de colectividad y la construcción de comunidad, no solo en tu centro de trabajo, en tu centro escolar, [es decir], participar activamente en las decisiones que te afectan directamente..., ahí está la construcción de la ciudadanía y así es como yo la ejerzo, desde que tengo uso de razón” (GFPP1).

Predomina en este colectivo la visión de una participación política institucionalizada, en la que las decisiones son colectivas y con base en procedimientos democráticos que sobrepasan la acción de votar. Esto no oculta la forma legitimadora del orden establecido, que determina como base de la democracia la forma procesual de la toma de decisiones.

La respuesta coincide con la dada mayoritariamente en la ECP, en la pregunta: Para resolver un problema que le afecta a usted y a otras personas iha tratado de...? Respuesta: “organizarse con otras personas afectadas” (44.7\%). En este sentido, prevalece tanto en la sociedad hidalguense como en los universitarios con participación convencional una comprensión de la participación institucional que legitima el orden establecido. Esto coincide con lo señalado por Brussino y Rabbia (2009), para quienes: "Las asociaciones normativas de las prácticas convencionales [son] posiciones legitimadoras..., [que] permiten enmarcar algunas de las formas en las que se han comprendido la relación de los jóvenes con la política” (p. 280).

Los jóvenes miembros de partidos políticos valoran positivamente su integración en los mismos, tanto desde un punto de vista personal como colectivo. Y además lo hacen desde extremos ideológicos.

"Cuando tuve la oportunidad de integrarme a un partido político no dude en integrarme al PAN. Estoy convencida, sobre todo porque el partido cree en los jóvenes, y eso es algo que siempre me ha gustado de él... El ejemplo está en que yo, gracias a Dios, pude lograr algo y estar dentro de los órganos más importantes del partido" (GFPP4). 
"La construcción que hago al interior del partido no es por defender una bandera o un sistema político electoral sino por defender las causas de la gente, y además hacer construcciones de una agenda política que les sirva para poder seguir avanzando en las conquistas sociales" (GFPP2).

Este interés y simpatías mostradas por los partidos políticos en los que militan y en la participación política de los jóvenes con participación convencional entrevistados es opuesto al expresado mayoritariamente por los jóvenes mexicanos, quienes según la ENJUV (2012) manifestaban un desinterés mayoritario por la política (89.29\%) y no simpatizar por los partidos políticos (45.2\%); y con la ECP, muestra significativa para Hidalgo, que señalaba un interés por la política de poco o nada del $77.4 \%$. La participación de estos jóvenes en partidos políticos debe entenderse de forma minoritaria, pues según la ECP sólo el 4.9\% participaba en partidos políticos. Esto es concordante, al ser los entrevistados universitarios, con lo que señala Sabucedo (1996):

La educación les posibilita a los individuos la oportunidad de adquirir los recursos y las habilidades cognitivas, además de la información necesaria, y despierta inquietudes y preocupaciones éticas y de responsabilidad cívica por el mundo social y político en el que viven (citado por Arias y Alvarado, 2015, p. 585).

Este perfil de joven se siente cómodo en los partidos políticos.

"Soy liberal, concuerdo con la ideología de mi partido porque creo en las libertades del ser humano: en la libertad de pensamiento, de propiedad, de acción, de decisión... Soy un joven que actualmente es precandidato a regidor por Mineral de la Reforma” (GFPP5).

Esto contrasta fuertemente con la confianza que los mexicanos tienen en los partidos políticos, ya que solo el $9 \%$ confía en ellos según la Corporación Latinobarómetro (2017, p. 27). Lo que quiere decir que este país se sitúa entre los tres que menos confían en los partidos políticos, solo detrás de Brasil (7\%) y El Salvador (8\%). También está en concordancia con la opinión de que a las entidades municipales - predominantemente gobernadas por miembros de partidos políticos- no le interesan lo que piensan los ciudadanos (91\%), resultado obtenido en la ECP. Las causas de esta desconfianza de los mexicanos en los partidos políticos las sitúa Del Tronco (diciembre de 2012) en: (1) la no identificación partidaria; (2) que los partidos defienden intereses particulares y no los de la ciudadanía; y (3) que los partidos son innecesarios para que el gobierno funcione. 
Los jóvenes con participación partidaria opinan que su participación resulta eficiente y eficaz para los partidos políticos en los que militan. De esta forma:

“Creo que [los jóvenes en el partido] sí hemos dado buenos resultados... Lo que hicimos fue la construcción de una agenda política que tratamos de impulsar como jóvenes... Pasábamos del modelo característico de un militante..., que se ciñe a las reglas de participación al interior de su partido, a la línea política que maneja la dirigencia y de la inducción de la actividad política de los jóvenes. Impulsamos la ley sobre la regulación de la mariguana recolectando 125 mil firmas, logramos recolectar las firmas como jóvenes, como organismo juvenil. La presentamos en la cámara de diputados. Actualmente se está discutiendo en las comisiones correspondientes. Impulsamos una ley, en cada uno de los congresos estatales, sobre la tarifa cero, es decir, tarifas preferenciales para los estudiantes... Hemos logrado ingresar la ley en más de la mitad de los estados de la federación. Entonces, de alguna manera, vamos avanzando en la construcción de una agenda política de los jóvenes, desde los jóvenes y en interés de los jóvenes. A la par que construimos la participación política de los jóvenes, que básicamente está olvidada en todos los partidos" (GFPP2).

De nuevo esta valoración de los jóvenes con participación partidaria se sitúa en una posición minoritaria. Al respecto, como señala la ECP a la pregunta: "Para resolver un problema que le afecta a usted y a otras personas ¿ha tratado de...?”, sólo el 11\% contestó que: "procurar el apoyo de partidos políticos o de diputados y senadores".

De hecho:

En el ámbito de los estudios de juventud, se suele esbozar como razones de la apatía o la desafección de los jóvenes por la política, la lejanía existente entre las prácticas y las rutinas que caracterizan la dinámica partidaria y las sensibilidades y prácticas juveniles que según algunos estudiosos (Valenzuela, 2007; Urresti, 2000; Reguillo 2000; Botero y Torres 2008) están más cerca del arte, la estética y la cultura (Acosta, 2011, p. 53).

Hasta aquí se ha visto, a través de las opiniones de los jóvenes universitarios hidalguenses entrevistados y participantes en los grupos focales, las formas y características que adquiere la participación política convencional que realizan los que la suscriben, así como su confianza en las instituciones. A continuación se describen ambos aspectos para los participantes no convencionales. 


\section{La participación no convencional de los jóvenes universitarios hidalguenses}

Los movimientos sociales se mueven principalmente en este tipo de participación, tomando como instrumentos de acción política: las marchas, los paros, las tomas de espacios públicos y los bloqueos y teniendo en cuenta las oportunidades políticas tal y como las definen Lipsky, 1970 y Eisinger, 1973, citados por McAdam (1999).

Por otra parte, sus formas de relación y comunicación han cambiado con el tiempo; puesto que ahora internet, sobre todo las redes sociales, es la forma de interrelación que ha fomentado el debate y la participación juvenil (Feixa, 2014).

Los activistas de los movimientos sociales son los más partidarios de la acción colectiva no convencional, incluso de la denominada disruptiva ${ }^{31}$, que puede considerarse como un subtipo de aquella. En este sentido:

"Por su naturaleza, los modos de participación política no convencional o de protesta utilizados generalmente por los movimientos sociales son disruptivos del status quo y van en contra del modelo tradicional de intermediación de intereses de las democracias contemporáneas" (Somuano, 2007, p. 32).

No sólo los activistas en movimientos sociales apoyaron las acciones disruptivas, también los no participantes lo hicieron. De este modo:

"Creo que los movimientos sociales son importantes, son parte del cambio social. Por ejemplo, los $43^{32} \ldots[$ se $]$ hicieron pintas, [se $]$ tomaron camiones. Los tomamos como vándalos... No creo que los cambios vengan con flores... Cómo puedes hacer cumplir las leyes si el propio Estado no cumple con las leyes" (GFNP1).

De hecho, el movimiento que cita el participante: "se ha convertido en una bandera de lucha que exige mayor democracia y justicia social, constituyéndose en un actor que representa la movilización más importante en la actualidad" (Ramírez, 2016, p. 71).

Los discursos positivos hacia la participación no convencional son consecuencia en muchos casos de una falta de confianza en los mecanismos convencionales de participación. Es el caso siguiente.

31 Las principales acciones disruptivas son la ocupación de espacios públicos y bloqueo de lugares públicos, como señalan Martí y Llamazares (2010).

32 Se refiere a algunas de las movilizaciones que se realizaron por la desaparición forzada de los 43 estudiantes de la Escuela Normal Rural Isidro Burgos de Ayotzinapa, ocurrida en Iguala en la noche del 26 y madrugada del 27 de septiembre de 2014. 
“Tengo una muy mala impresión de lo que sucede aquí. He tenido la oportunidad de observar algunos grupos de jóvenes que se han unido a los grupos políticos de poder, por no decir directamente los jóvenes Priistas. He visto que esa es la única participación que tienen, siendo que es de derecha. Por otro lado, siento que los jóvenes se han apartado de eso y dicen: "yo no quiero meterme en política, yo quiero abrir mis espacios culturales, quiero abrir mis espacios de dialogo, sociales, y simplemente me marginan”. Entonces, existen los de derecha y existen los que están en otra cosa que nada tiene que ver con el gobierno. Se manifiestan, pero artísticamente y de otras maneras” (EMS1).

A este respecto, los jóvenes mexicanos, según datos de la Encuesta Nacional de Juventud de 2006, presentan: “desaprobación y desconfianza hacia los partidos políticos y autoridades públicas que invisten las instituciones de la democracia y los poderes legislativo, ejecutivo y judicial” (Vázquez, 2011, p. 55).

Los activistas de movimientos sociales defienden la legitimidad de este tipo de acciones, considerándolas como un ejercicio de ciudadanía. De hecho, les parece la forma de participación ciudadana por excelencia. De esta forma:

"Creo que: desde el hecho de salir a las calles y participar activamente, exigiendo cosas..., ya desde ahí empiezas a participar. Es como tu responsabilidad social” (GFMS1).

De hecho (Flanagan et al., 2007) "sugieren que las medidas de compromiso cívico debieran incluir formas de activismo no convencional [y] Haste y Hogan (2006) plantean que la política no convencional ha pasado de tener un rol periférico a central en el funcionamiento de las democracias (citados por Varela, Martínez y Cumsille p. 718).

A pesar de la centralidad de la participación no convencional en la política, según los autores señalados, los participantes en las entrevistas y grupos focales muestran mayoritariamente un discurso pesimista con respecto a la efectividad de estas acciones, así:

"Yo he estado en varios movimientos desde pequeño y, pues, siempre se hacen marchas y no hay ninguna respuesta del gobierno. Es muy difícil que después de una marcha haya un dialogo... Luego las personas se van frustrando y dejan de participar. Llegan nuevas personas, pero ya no es lo mismo. Es como cansado, aquí en el Estado [de Hidalgo]” (GFMS6). 
También surgen consideraciones sobre la falta de cultura política cívica ${ }^{33} \mathrm{y}$ sobre la incapacidad de los hidalguenses de organizarse de forma horizontal, sin liderazgos o cacicazgos.

"Lo vemos con el TuzoBus, mucha gente va marchando y me preguntan: ¿Qué es lo que sigue?, ¿Qué vamos a hacer? Y yo me digo, $\operatorname{chin}^{34} \ldots$ Yo no me puedo meter en eso, ósea, si soy ciudadano y si me afecta el TuzoBus, pero finalmente yo creo que son los vecinos los que tienen que ponerse de acuerdo, se tiene que escuchar la propuesta de todos. Tal vez la gente está muy acostumbrada a que haya dirigentes en todos los movimientos, que les propongan y que solo tengan que decir que sí o que no" (GFMS2).

En el sentido expresado por el participante, una investigación llevada a cabo por Taguenca, Sampedro y Ortiz (2010) mostraba opiniones semejantes en los entrevistados, jóvenes universitarios hidalguenses. Al respecto, éstos creían: "que el desarrollo y extensión de la cultura política son mínimos en México. En este sentido la caracterizan como deficiente" (p. 84).

El movimiento social en el que estuvieron más implicados los estudiantes hidalguenses, según los entrevistados, fue el de solidaridad con la desaparición forzada de los 43 de Ayotzinapa ${ }^{35}$. Entre ellos, los que forman parte del colectivo "22 de octubre", que es una organización estudiantil que surgió durante las manifestaciones por la desaparición de los 43 de Ayotzinapa.

La noticia de su desaparición forzada, que se había extendido por toda la República, tuvo un gran impacto en los estudiantes universitarios del Estado de Hidalgo, quienes pegaron carteles en sus sedes de estudio, discutieron en asambleas acciones de protesta y se movilizaron a través de manifestaciones y tomas de instalaciones universitarias. Su organización fue horizontal y asamblearia.

El 5 de noviembre de 2014 se produjo un paro simbólico de dos horas, durante el cual se organizaron actividades artísticas y culturales. Finalmente el

33 La cultura cívica puede definirse como una cultura política participante donde la cultura política y la estructura política son congruentes Los rasgos asociados a la cultura cívica son: una cultura participativa muy desarrollada y extendida, un involucramiento del ciudadano con la política y un sentido de obligación para con la comunidad, una amplia convicción de que se puede influir sobre las decisiones gubernamentales, gran número de miembros activos en diversos tipos de asociaciones sociales voluntarias y gran orgullo por el sistema político (Almond y Verba, 2001).

34 Expresión que puede traducirse como: "no se sabe lo que procede".

35 Esto no quiere decir que no hubiera estudiantes universitarios involucrados en el movimiento \#YoSoy132. Aunque los entrevistados y participantes en los grupos de discusión no hicieron énfasis en su participación en este movimiento, y sí en el de los 43 desaparecidos de Ayotzinapa. 
movimiento derivó en otras luchas sociales como indican los siguientes entrevistados.

"Inicialmente fue por hermandad y por identificación; porque así como fueron estudiantes de una escuela rural pudimos ser nosotros. Con el tiempo el movimiento por los 43 reivindicaría otras luchas sociales” (EMS1).

"Ahorita estamos muy metidos en lo que pasa en el TuzoBus"36 (GFMS3).

Poco a poco el movimiento fue decayendo, y en abril de 2016 la falta de participación ya era notoria. Pese a ello, el movimiento solidario con los 43 de Ayotzinapa supuso un antes y un después en el activismo universitario hidalguense, mostrando que los estudiantes de la entidad son solidarios y tienen capacidad organizativa y de movilización. No son, como se pensaba, tan pasivos e indiferentes hacia los acontecimientos sociales y políticos.

El movimiento solidario con los 43 de Ayotzinapa se caracterizó por el uso intensivo de las nuevas tecnologías de la información y la comunicación, especialmente a través de redes sociales en internet; situándose en un enfrentamiento con el gobierno mexicano, por su falta de respuesta ante la sociedad civil, quien niega la "verdad histórica” que aquél le ofrece.

Las manifestaciones que se organizaron en todo el país por la desaparición de los 43 de Ayotzinapa fueron generalizadas y en Hidalgo dejaron imágenes tan sensibles como la que a continuación se presenta.

\footnotetext{
36 El TuzoBus es un sistema de transporte público mediante autobuses. Su peculiaridad es que confina un carril, con lo que complica la circulación vehicular del transporte privado. El problema surgió, porque vino a sustituir en Pachuca, como transporte urbano público, a las "combis", cierto tipo de autos usados para el transporte público, que tenían una capacidad para transportar a 17 personas sentadas y que por su tamaño y rutas llegaban a todas las colonias, dejando al pasajero prácticamente en el lugar donde quería pararse. Pues bien, los pequeños transportes -"servidores" usados para unir a las colonias con las paradas del TuzoBus no tenían el alcance de las "combis" y, por si esto fuera poco, el precio del transporte público subió. Esto causo enfado en la población pachuqueña que usa este tipo de transporte, enfado que se acrecentó por la falta de información sobre su uso y por la falta de transparencia en la decisión pública que afectó a tantos usuarios.
} 
Figura 3. Joven manifestante por los 43 de Ayotzinapa.

Plaza Juárez, Pachuca de Soto, Hidalgo, octubre de 2014,

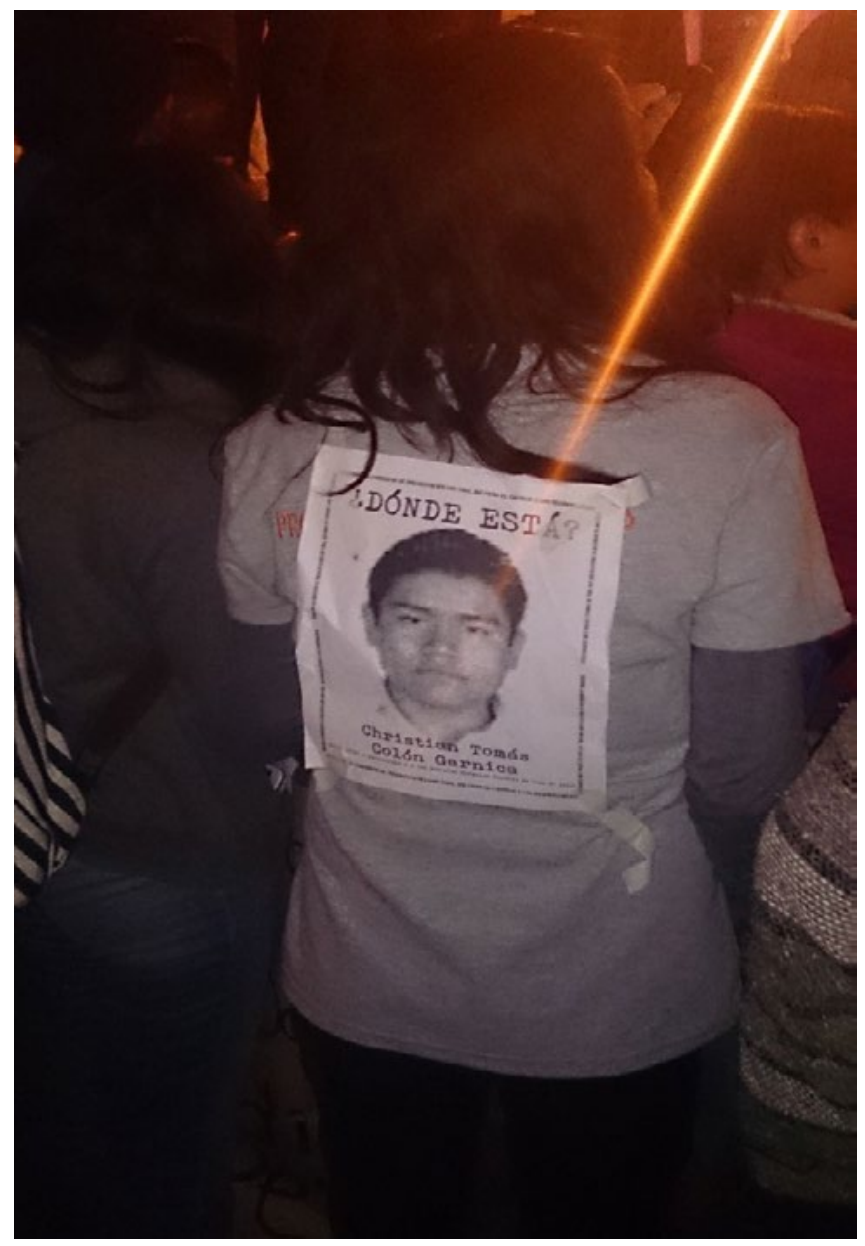

Fuente: autoría propia.

En los no participantes, sin embargo, surgen discursos de desconfianza hacia las acciones no convencionales. Esto es debido a que creen se hallan infiltradas por "grupos de porros" ${ }^{37}$ o miembros de los cuerpos policiales. En este sentido:

37 Son "grupos pandilleros al servicio de las autoridades universitarias y el gobierno" (Ordorika, 2008, p. 462) 
"Las cuestiones de vandalismo que ocurren son [provocadas] muchas veces por grupos de choque. Ha sucedido aquí en las marchas del TuzoBus: había unos chicos que solo estaban haciendo destrozos y ni siquiera eran del movimiento... Es difícil intentar controlar ese tipo de cuestiones, identificar a los grupos. De hecho, algunos grupos son metidos por los mismos partidos políticos. A veces, cuando quieres ir a manifestarte, vas con cierto temor de no saber qué va a pasar" (GFNP9).

La participación por medio de vínculos con grupos primarios, comunitaria, es utilizada y defendida por todos los tipos de jóvenes estudiantes tenidos en cuenta: no participantes y participantes en partidos políticos, la sociedad de alumnos y activistas en movimientos sociales. Al respecto, dos jóvenes militantes en partidos políticos dicen:

"Participación, creo que toda participación es política. La ciudadanía se ejerce a partir de participar en las cosas más ínfimas: desde la organización en tu calle, en tu colonia, con tu familia. [Todas ellas] son decisiones políticas, La ciudadanía tiene que ser participación” (GFPP1).

"Yo lo veo en el entorno donde vivo, en la colonia donde vivo. Los vecinos estamos organizados. No hablamos para nada de partidos políticos, sin embargo estamos organizados porque han robado más de 10 casas en la colonia en un mes o dos meses" (GFPP4).

\section{Conclusiones}

Los universitarios hidalguenses se sitúan en un contexto sociopolítico adverso en relación con sus posibilidades de participación política. En este sentido, en la entidad permanece sin alternancia, con un partido predominante y una cultura política súbdita o parroquial con características clientelares y con permanencias de cacicazgos políticos y sociales que afectan sus posibilidades de desarrollo democrático.

El Estado de Hidalgo se caracteriza por: rezago educativo y de ingresos con respecto a la media nacional y a otras entidades federativas, una gran heterogeneidad, con varios grupos de pueblos originarios dentro de él (Náuatl y Otomí principalmente) y poco crecimiento económico. 
Los jóvenes universitarios hidalguenses, al igual que la mayoría de los ciudadanos de esta entidad, prefieren la democracia pero están desinformados, no tienen interés, participan poco, desconfían de las autoridades democráticas y acatan poco las decisiones democráticas mayoritarias que les afectan. La preferencia por la democracia es independiente de: edad, género, nivel educativo e ingreso. Los hombres y los que tienen un mayor nivel educativo tienen un poco más de información política que las mujeres y los que tienen un nivel educativo más bajo. La información política es independiente de la edad y el nivel de ingreso.

Quienes tienen un mayor nivel de estudios son los más interesados en política. Además, el interés por la política es independiente de la edad, el género y el ingreso. Son los mayores de 30 años y los que tienen un mayor nivel de estudios los que están asociados a mayores niveles de participación en Hidalgo. No existe asociación en la confianza en las autoridades y en el acatamiento de las decisiones tomadas por la mayoría con la de edad, el género, el nivel de ingresos y el nivel educativo. En estas variables los resultados por edad -los de los jóvenesson similares a los obtenidos en la Encuesta Nacional de Valores de la Juventud -ENVAJ (2012).

Los resultados son sin embargo preocupantes, en cierto sentido, ya que los porcentajes bajos de confianza en las instituciones democráticas -mostrado, por ejemplo, en baja participación, desinterés y desinformación- se traducen en: "organización de la desconfianza”, "contrapoder ciudadano” y "contracultura democrática”; aspectos, todos ellos, que dificultan enormemente el funcionamiento de la democracia y sus instituciones.

No obstante lo anterior existen, en otro sentido, también lecturas esperanzadoras de la "organización de la desconfianza”, “contrapoder ciudadano” y “contracultura democrática”. Ejemplos de ello, lo encontramos en el concepto de "ciudadanía insurgente" en Holston (1999), quien piensa que la "organización de la desconfianza" es una muestra de praxis democrática que opone espacios de ciudadanía al proyecto político moderno que pretende absorberla en el plan de construcción del Estado.

Además, la desconfianza hacia las instituciones de la democracia representativa no es necesariamente una apuesta reactiva, sino que puede ser un síntoma de movimiento a favor de su profundización o de democratización, es decir de apuesta por una democracia más participativa (De Sousa Santos, 2004).

Se encontraron tres tipos de universitarios hidalguenses en relación con su participación política: no participantes, militantes de partidos políticos y sociedades de alumnos y, finalmente, activistas en movimientos sociales. 
Los tres tienen discursos distintos sobre la participación: experiencial, realismo y politización ${ }^{38}$, respectivamente; y tipos de participación distintos: de baja o nula participación, y de participación convencional y no convencional. Los primeros presentan un discurso sobre la participación basado en el temor y la experiencia. Los segundos reconocen, en su opinión, la existencia de otros tipos de participación política y valoran positivamente su integración en los partidos y asociaciones, y además defienden el impacto de la agenda política en la sociedad. Los últimos presentan en sus manifestaciones: falta de confianza en los mecanismos existentes de participación convencional y en las instituciones democráticas y una creencia de que en Hidalgo no existe verdaderamente una cultura cívica.

\section{Referencias}

Acosta, G. L. (diciembre, 2011). Jóvenes en la política partidaria. Una aproximación a las organizaciones de juventud, vinculadas a los partidos políticos en Colombia. Anagramas, 10(19), 51-68. Recuperado de: http://www.scielo.org.co/pdf/angr/v10n 19/v10n 19a4.pdf

Acosta, L. y Tapia, A. (2003). Jóvenes Mexicanos del siglo XXI: Encuesta Nacional de Juventud 2000. Hidalgo, México D.F.: Instituto Mexicano de la Juventud.

Adorno, T. (1973). La disputa del positivismo en la sociología alemna. Barcelona-México D.F.: Ediciones Grijalbo S.A.

Aguilera, O. (2016). Jóvenes pingüin@s. Movimiento estudiantil y Escuela Secundaria en Chile. En C. Feixa, y P. Oliart, Juvenopedia. Mapeo de las juventudes iberoamericanas (pp. 231-241). Barcelona: NedEdiciones.

38 Existe una amplia bibliografía sobre los procesos de politización juvenil, que en la última década han sido ampliamente estudiados en Latinoamérica y España. En este sentido, a modo de ejemplo, sin ser exhaustivos, señalamos los siguientes: Argentina: Kriger (2014) y Bonvillani y Roldán (2017); España: Benedicto y Morán (2014); Chile: Gamboa y Pincheira (2009) y PNUD (2015); Brasil: Dias y de Oliveira (orgs.) (2013); México: Modonesi (mayo-junio de 2014), Monterde (octubre de 2015) y Ramírez (coord.) (2016); Colombia: Henao y Eugenia (julio-diciembre de 2009); Venezuela: Guzmán y Scheifes (noviembre de 2016). Si bien estos trabajos tienen en común focalizarse en la juventud y sus procesos de politización, lo hacen desde objetivos distintos, en los que las coyunturas nacionales juegan un papel importante. En nuestro trabajo la coyuntura del \#YoSoy132, que aparece en las entrevistas y en grupos focales analizados, y que refiere también Modonesi (2014), Monterde (octubre de 2015) es constitutiva, junto al movimiento por los 43 de Ayotzinapa, también citado por los entrevistados y por Ramírez (coord.) (2016), del proceso de politización juvenil y universitaria más importante que ha tenido México en lo que llevamos de siglo XXI. 
AMAI. (mayo, 2008). Nivel socioeconómico AMAI. Recuperado de: http://www. inegi.org.mx/rne/docs/pdfs/mesa4/20/heribertolopez.pdf

Animal Político. (agosto 3 de 2015). México, el más corrupto de los 34 miembros de la OCDE: Índice de Percepción de la Corrupción. Animal Político. Recuperado de: http://www.animalpolitico.com/2016/o1/mexico-el-mascorrupto-de-los-34-miembros-de-la-ocde-indice-de-percepcion-de-la-corrupcion/

Arias, A. M., y Alvarado, S. V. (2015). Jóvenes y política: de la participación formal a la movilización informal. Revista Latinoamericana de Ciencias Sociales, Niñez y Juventud, 13(2), 581-594. Recuperado de: http://www.scielo.org. $\mathrm{co} / \mathrm{pdf} / \mathrm{rlcs} / \mathrm{v} 13 \mathrm{n} 2 / \mathrm{v} 13 \mathrm{n} 2 \mathrm{aO} 3 . \mathrm{pdf}$

Beck, U., y Beck-Gernsheim, E. (2003). La individualización. El individuo institucionalizado y sus consecuencias sociales y políticas. Barcelona: Paidós.

Benedicto, J., y Morán, M. L. (2014). ¿Otra clase de politización? Representaciones de la vida colectiva y procesos de implicación cívica de los jóvenes en situación de desventaja. Revista Internacional de Sociología (RIS), 72(2), 429-452. doi:10.3989/ris.2013.02.21

Bobbio, N. (2009). Democracia: las técnicas. En N. Boobio, Teoría general de la política (pp. 449-508). Madrid: Trotta.

Bonvillani, A. y Roldán, M. (2017). Politización de los cuerpos juveniles: la marcha de la gorra como performance multitudinaria. Aposta revista de ciencias sociales, 165-203.

Brussino, S., Rabbia, H. H. y Sorribas, P. (2009). Perfiles sociocognitivos de la participación política de los jóvenes. Revista Interamericana de Psicología, 43(2), 279-287. Recuperado de: http://www.redalyc.org/ $\mathrm{html} / 284 / 28412891009 /$

Cano, J. (2015). Política y generaciones ¿đónde están los jóvenes? Horizaontal. Recuperado de: http://horizontal.mx/politica-y-generaciones-donde-estan-los-jovenes/

Catells, M. (2013). Redes de indignación y esperanza. Madrid, España: Alianza Editorial. 
Colegio Mexiquense y Data Opinión Pública y Mercadeo. (diciembre 31 de 2014). Realización de 3200 encuestas para generar información cuantitativa sobre ciudadanía y participación. Recuperado de: https://www.dropbox. $\mathrm{com} / \mathrm{preview} /$ proyecto\%20ciudadan\%C3\%ADa\%20y\%20participaci\%C3\%B3n\%20pol\%C3\%ADtica/Nota\%20Metodologica.docx?role=personal

Colegio Mexiquense A.C. y Data Opinión pública y mercadeo (2014). Encuesta ciudadanía y participación. Una mirada desde lo local: Chihuahua, Estado de México, Hidalgo y Oaxaca. Toluca: Colegio Mexiquense.

Corporación Latinobarómetro. (2017). Informe 2017. Recuperado de: http:// www.latinobarometro.org/LATDocs/Fo0006433-InfLatinobarometro2017.pdf

De Sousa Santos, B. (2004). Reiventar la democracia. Reiventar el Estado. Quito: Ediciones Abya-Yala.

Del Tronco, J. (diciembre, 2012). Las causas de la desconfianza política en México. Perfiles Latinoamericanos, 20(40), 227-251. Recuperado de: http://www. scielo.org.mx/pdf/perlat/v20n40/v20n40a9.pdf

Dias, H. y de Oliveira, S. (orgs.) (2013). La juventud en el siglo XXI: dilemas y perspectivas. Goiânia: Canône.

Encuesta Nacional de Valores de la Juventud (ENVAJ) (2012). Encuesta Nacional de Valores en Juventud 2012. Resultados generales. Recuperado de: https:// www.imjuventud.gob.mx/imgs/uploads/ENVAJ_2012.pdf

ENCUP (2012). Resultados de la Quinta Encuesta Nacional sobre Cultura Política y Prácticas Ciudadanas ENCUP 2012. Recuperado de: http://www. encup.gob.mx/work/models/Encup/Resource/69/1/images/Resultados-Quinta-ENCUP-2012.pdf

ENVUD (2010). Encuesta Nacional de Valores: lo que une y lo que divide a los mexicanos. México D.F.: Fundación este país y Grupo Banamex.

Feixa, C. (2014). De la generación@a la \#Generación. La juventud en la era digital. Barcelona: NED ediciones. 
Fernández, A. (2003). Cultura política y jóvenes en el umbral del nuevo milenio. México D.F.: Instituto Mexicano de la Juventud.

Fernández, L. (1999). Algunas reflexiones a la participación política. Reflexión política, 1(1).

Gamboa, A. y Pincheira, I. (2009). Organizaciones juveniles en Santiago de Chile. Invisibles_Subterráneas. Santiago de Chile: LOM Ediciones/ ECO. Educación y Comunicaciones.

Gómez, S.; Tejera, Héctor; Aguilar, J.; Ramírez, J. y Díaz, O. F. (2012). Informe de la Encuesta Nacional de Cultura Política de los Jóvenes 2012. México D.F.: El Colegio de México. Recuperado de: http://www.culturapoliticajovenes.colmex.mx/wp-content/uploads/2017/o2/Informe-Encuesta-Final_20.-feb.2017-con-portada.pdf

González, R. y Hernández, J. E. (2017). La participación política juvenil en México y España. Una perspectiva comparada. En Lugo, B y Taguenca, J. A. Democracias. Una panorámica (pp. 173-200). UAEH: Pachuca, México.

Guzmán, J. y Scheifes, D. (noviembre, 2016). Procesos de politización de jóvenes de clase popular de Caracas. Recuperado de: https://issuu.com/josetato/docs/ guzman-scheifes_2016_teg_procesos

Henao, J. y Eugenia, V. (diciembre, 2009). Jóvenes y ciudadanías en Colombia: entre la politización social y la participación institucional. Revista Latinoamericana de Ciencias Sociales, Niñez y Juventud, 1405-1437. Recuperado de: http://www.redalyc.org/pdf/773/77314999010.pdf

Holston, J. (1999). Spaces of Insurgent Citizenship. En J. Holston (ed.). Cities and Citizenship (pp. 155-176). Durham and London: Duke University Press.

Instituto Nacional de Estadística y Geografía, INEGI. (2013). Anuario estadístico y geográfico de Hidalgo 2013. Aguascalientes: INEGI. Recuperado de: http:/ / sepladerym.hidalgo.gob.mx/medios/AEyGHgo 13.pdf

Instituto Nacional de Estadística y Geografía, INEGI. (2015). Principales resultados de la Encuesta Intercensal 2015 Estados Unidos Mexicanos. Aguascalientes: INEGI. Recuperado de: http://www.beta.inegi.org.mx/contenidos/ 
proyectos/enchogares/especiales/intercensal/2015/doc/eic2015_resultados.pdf

Instituto Nacional de Estadística y Geografía, INEGI. (2016). Anuario estadístico y geográfico de Hidalgo 2016. Aguascalientes: Gobierno del Estado de Hidalgo e INEGI. Recuperado el 3 de junio de 2017, de http://www.datatur. sectur.gob.mx/ITxEF_Docs/HGO_ANUARIO_PDF 16.pdf

Jorge, J. E. (s. f.). Factores que influyen en el interés por la política entre los argentinos: un análisis basado en evidencia empírica, Buenos Aires: Universidad Nacional de la Plata.

Krauze, E. (junio, 2016). El misterio de los Millennials. Reforma. Recuperado de: http://www.enriquekrauze.com.mx/joomla/index.php/opinion/97-art-critica-social/976-el-misterio-de-los-millennials.html

Kriger, M. (2014). Politización juvenil en las naciones contemporáneas. El caso argentino. Revista Latinoamericana de Ciencias Sociales, Niñez y Juventud, $12(2), 583-596$.

Maffesoli, M. (2009). El tiempo de las tribus. El ocaso del individualismo en las sociedades posmodernas. México D.F.: Siglo XXI.

Martí, S. y Llamazares, I. (2010). Un análisis de la política disruptiva en México. ¿Quiénes se movilizan y porqué lo hacen? XXIX Congreso Internacional de la Asociación de Estudios Latinoamericanos (pp. 1-21). Toronto: Asociación de Estudios Latinoamericanos. Recuperado de: http://campus.usal.es/ dpublico//areacp/democracialocal/pdfs/Protestadisruptiva.pdf

McAdam, D. (1999). Orígenes terminológicos, problemas actuales, futuras líneas de investigación. En D. McAdam, J. D. McCarthy, y M. N. Zald (Eds.). Movimientos sociales: perspectivas comparadas (pp. 49-70). Madrid: Istmo.

Megías, E. (2006). Jóvenes y política. El compromiso con lo colectivo. Madrid, España: FAD

Modonessi, M. (junio, 2014). Postzapatismo. Identidades y culturas políticas juveniles y universitarias en México. Nueva Sociedad, 136-152. Recuperado de: http://nuso.org/media/articles/downloads/4034_1.pdf 
Molina A. y Ponce, C. I. (2009). Una revisión sobre la cultura política de los jóvenes de CONAFE Hidalgo. Ponencia presentada en X Congreso Nacional de Investigación Educativa, Veracruz, 21-25, septiembre de 2009. Recuperado de: http://www.comie.org.mx/congreso/memoriaelectronica/v10/pdf/ area_tematica_06/ponencias/1659-F.pdf

Monterde, A. et al. (octubre, 2015). \# YoSoy132: ¿ Un nuevo paradigma en la política Mexicana? Recuperado de: http://in3-working-paper-series.uoc.edu/in3/ ca/index.php/in3-working-paper-series/article/download/2066/206611280-1-PB.pdf

Muñoz, G. (2016). Jóvenes digitales. Cuerpos con agencia, en Colombia. En C. Feixa y P. Oliart (coords.). Juvenopedia. Mapeo de las juventudes iberoamericanas (pp. 71-89). Barcelona: NedEdiciones.

Ochoa, L. F. (s.f.). Matriz de tendencias en filosofía de la ciencia. Recuperado de: https://www.researchgate.net/profile/Luis_Ochoa_Rojas/publication/303518346_MATRIZ_DE_TENDENCIAS_EN_FILOSOFIA_DE_LA_CIENCIA/links/5745ccfco8ae9f74 1b430da4.pdf?inViewer=o\&pdfJsDownload=o\&origin=publication_detail

Ordorika, I. (2008). Violencia y porrismo en la educación superior en México. Anuario educativo mexicano: visión retrospectiva, año 2005, 459-475. Recuperado de: http://www.ses.unam.mx/integrantes/uploadfile/iordorika/26\%20Ordorika.pdf

PNUD. (2015). Desarrollo Humano en Chile. Los tiempos de la politización. Santiago de Chile: PNUD. Recuperado de: http://hdr.undp.org/sites/default/files/ informe_2015.pdf

Ramírez, M. Á. (2016). Pensar los movimientos sociales en el siglo XXI. En M. Á. Ramírez (Coord.). Movimientos Sociales en México. Apuntes teóricos y estudios de caso (pp. 61-110). Recuperado de: http://www.redmovimientos.mx/2016/wp-content/uploads/2016/10/Impresio\%CC\%81n-Movimientos-sociales_PDF-1.pdf

Ramírez, M. Á. (Coord.) (2016). Movimientos Sociales en México. Apuntes teóricos y estudios de caso. Recuperado de: http://www.redmovimientos.mx/2016/ wp-content/uploads/2016/10/Impresio\%CC\%8 1n-Movimientos-sociales_PDF-1.pdf 
Reguillo, R. (2013). Jóvenes y estudios culturales. Noas para un balance reflexivo. En J. M. Valenzuela (coord.). Los estudios culturales en México (pp. 354379). México D.F.: Consejo Nacional para la Cultura y las Artes y Fondo de Cultura Económica.

Reguillo, R. (2015). Primaveras políticas en el otoño civilizatorio: Paisajes insurrectos. En M. E. Sánchez, y Ó. Soto (Eds.) ¿Qué es el poder hoy? (pp. 1-22). Recuperado de:https://www.academia.edu/19876995/Primaveras_Pol\%C3\%ADticas_en_el_Oto\%C3\%B1o_Civilizatorio_Paisajes_Insurrectos

Sánchez, M. F. (2007). La cultura política de los jóvenes en el Estado de Hidalgo (Tesis de licenciatura). Universidad Autónoma del Estado de Hidalgo. Recuperado de: https://repository.uaeh.edu.mx/bitstream/bitstream/ handle/123456789/10810/La\%20cultura\%2Opolitica\%2Ode\%20los\%20 jovenes.pdf? sequence $=1$

Sandoval, J. y Hatibovic, F. (2016). Acción política de jóvenes chilenos participantes de organizaciones universitarias. XII Congreso Español de Sociología. Gijón: Asociación Española de Sociología.

Secretaría del Trabajo y Previsión social (abril, 2017). Hidalgo. Información laboral. Ciudad de México: Secretaría del Trabajo y Previsión Social. Subsecretaría de Empleo y Productividad Laboral. Recuperado de: http://www. stps.gob.mx/gobmx/estadisticas/pdf/perfiles/perfil\%2ohidalgo.pdf

Somuano, M. F. (2007). Movimientos sociales y partidos políticos en América Latina: una relación cambiante y compleja. Política y cultura(27), 31-53. Recuperado de: http://www.scielo.org.mx/pdf/polcul/n27/n27a3.pdf

Suárez, C., Del Morral, G. y González, M. T. (2013). Consejos prácticos para escribir un artículo cualitativo publicable en Psicología. Psychological Intervention (22), 71-79.

Taguenca, J. A. y Lugo, B. (2011). Percepción de la democracia de los jóvenes mexicanos. Política y gobierno, II Semestre, XVIII(2), pp. 179-230. Recuperado de: http://www.scielo.org.mx/pdf/pyg/v18n2/v18n2a1.pdf

Taguenca, J. A. (2011). Jóvenes mexicanos y política. Una relación compleja y ambivalente. Pachuca de Soto: Universidad Autónoma del Estado de Hidalgo. Recuperado de https://www.uaeh.edu.mx/investigacion/producto. php? producto $=5078$ 
Taguenca, J. A. (2012). La opinión de los jóvenes universitarios de Hidalgo, México. Un análisis desde la teoría de campo. Convergencia. Revista de ciencias políticas y sociales, 19(60), 45-77.

Taguenca, J. A., Sampedro, O. A. y Ortiz, J. (2010). Opinión sobre la política de los jóvenes universitarios hidalguenses: un estudio de narrativas y entrevistas desde la cultura política. En C. R. Rodríguez y L. Raesfeld. Hidalgo: educación, cultura y sociedad (pp. 75-92). Pachuca de Soto: Universidad Autónoma del Estado de Hidalgo. Recuperado de: https://www.uaeh.edu. $\mathrm{mx} /$ investigacion/productos/5834/hidalgo_educacion_cultura_y_sociedad.pdf

Taguenca, J. A. (2013). La cultura política de los jóvenes universitarios en Hidalgo: un estudio sobre sus opiniones ya actitudes con respecto a la democracia. Tla-Melaua, Revista de Ciencias Sociales. Nueva época, Año 6(33), 6-24. Recuperado de http://www.apps.buap.mx/ojs3/index.php/tlamelaua/article/view/33/38

Trejo, L. (3 de agosto, 2017). Cae actividad económica 1.9\% en primer trimestre. Libre pon convicción El independiente de Hidalgo, p. 18.

Urteaga, M. (2011). La construcción juvenil de la realidad. Jóvenes mexicanos contemporáneos. México D.F.: Universidad Autónoma Metropolitana y Juan Pablos Editor.

Váquez, C. A. (junio, 2011). La participación ciudadana juvenil como un recurso externo al Gobierno. Revista Latinoamericana de Ciencias Sociales, Niñez y Juventud, 9(1), 45-59. Recuperado de: http://www.redalyc.org/ pdf/ 773/77320072001.pdf

Varela, E., Martínez, M. L. y Cumsille, P. (2015). ¿Es la participación política convencional un indicador del compromiso cívico de los jóvenes? Universitas Psychologica, 14(2), 715-730. doi:doi:10.11144/Javeriana.upsy 14-2.eppc

Vargas, P. (1990). Cultura política y elecciones en Hidalgo. Nueva Antropología, 131-145. Recuperado de: https://revistas-colaboracion.juridicas.unam. $\mathrm{mx} /$ index.php/nueva-antropologia/article/download/15571/13902 
Vargas, P. (1990). Cultura política y elecciones en Hidalgo. Nueva Antropología, 131-145. Recuperado de: https://revistas-colaboracion.juridicas.unam. $\mathrm{mx} /$ index.php/nueva-antropologia/article/download/15571/13902

Woldenberg, J. (diciembre, 2014). Democracia y desesperanza. Letras libres (192). Recuperado de: https://www.letraslibres.com/mexico/democracia-y-desesperanza 